\title{
Assessment of the effect of non invasive laser on the process of healing of an extraction wound by infrared thermography: preliminary study
}

\author{
Hana Fikáčková ${ }^{1,3}$, Blanka Navrátilová $^{3}$, Ivan Dylevskýy $^{2,4}$, Leoš Navrátil ${ }^{1,2}$, Radek Jirman ${ }^{5}$ \\ ${ }^{1}$ Charles University, $1^{\text {st }}$ Medical Faculty, Institute of Biophysics and Informatics, Praha, Czech Republic \\ ${ }^{2}$ University of South Bohemia, České Budějovice, Faculty of the Health and Social Studies, Department of \\ Radiology, Czech Republic \\ ${ }^{3}$ Private stomatosurgery practice, Praha, Czech Republic \\ ${ }^{4}$ Charles University, Department of Anatomy and Biomechanics Faculty of Physical Education and Sport, \\ Praha, Czech Republic \\ ${ }^{5}$ Charles University, $1^{\text {st }}$ Medical Faculty, Department of Stomatology, Praha, Czech Republic
}

\begin{abstract}
Summary
The purpose of this preliminary, double-blind, placebo-control study was to evaluate the effect of GaAlAs diode laser on wound healing and pain reduction in patients after extraction of impacted lower third molars by infrared thermography. Material and methods: The study population of two patients was divided into group A treated by GaAlAs diode laser with a wavelength $830 \mathrm{~nm}$ and maximal output power of $100 \mathrm{~mW}$ and group B treated by placebo laser. Therapeutic Schedule: The energy density per point was $12 \mathrm{~J}$, treatment time 2 minutes, the total energy density for one treatment session was $36 \mathrm{~J}$. Treatment intervals were 10 minutes after extraction, 1 and 3 days after extraction. Patients in group B were treated with a placebo probe in the same schedule. Patients evaluated the level of pain and swelling on $100 \mathrm{~mm}$ Visual Analog Scale. Thermographic measurements were performed by ThermaCAM ${ }^{\mathrm{TM}}$ SC 2000 before extraction, 30 minutes after extraction and on the 1st, 3rd, 5th, 8th days. Results: The patient treated by active laser reported more pain and swelling during the first week after tooth extraction than the patient treated by placebo laser. However, the comparison of thermograms of patients treated by placebo and active laser showed the acceleration of wound healing after extraction in the patient treated with GaAsAl diode laser. Conclusion: The treatment by GaAlAs diode laser, $830 \mathrm{~nm}$ and total energy density for one treatment session $36 \mathrm{~J}$ had a stimulation effect on the healing process but did not lead to reduction of pain and swelling in the patient after dental surgery.
\end{abstract}

Keywords: GaAlAs diode laser - wound healing - pain - infrared thermography - tooth extraction

\section{INTRODUCTION}

Surgical extractions of semi-retinal and retinal lower wisdom teeth are the most common stomatosurgical operations. Impacted lower molar extraction is connected with an inflammatory reaction of the organism, pain, swelling and momentary limitation of mouth movements. A low level laser therapy has been reported as an effective tool for treatment of post-surgical conditions because of its analgesic, anti-inflammatory and stimulating effect on tissue
(Simunovic et al. 2000, Navratil et al. 2000, Tunér and Hode 1999).

Determining the level of pain often becomes a criterion for evaluating the effect of treatment efficacy. However, assessment of the level of pain is a subjective evaluation easily affected by the patient's psychical condition. Since an inflammatory reaction of the organism is accompanied by local increased blood-flow to the inflicted area that results in the increasing of skin temperature, infrared thermography appears to be a promising research tool for an objective monitoring of the 
inflammatory reaction (Biagioni et al. 1996, Ventä et al. 2001). Infrared thermography is a diagnostic method based on its ability to record infrared radiation emitted by the skin and convert it into electronic video signals. Infrared thermography is unique in its capability to show physiological changes.

The objective of this preliminary study was to assess the efficacy of the low level laser on the inflammation reaction associated with extraction of impacted lower third molars evaluated by infrared thermography.

\section{MATERIAL AND METHODS}

The pilot study population consisted of eight patients. However, six of these patients had to be excluded from this study for reasons mentioned in table 1 . The same treatment conditions were kept only in two patients. These two patients attended for removal of impacted third molars from orthodontics indication. Radiographic classification of the position of the third molars was made from panoramatic radiographs according to Pell and Gregory classification (Garcia et al. 2000). The location of the wisdom tooth was defined as level C: the impact tooth is below the cervical line of the second molar. Ramus relationship/space available was defined as class 3: all or most of the third molar is in the ramus of the mandible. The patients were free of pain at the time of the study. Patients had a negative medical history, were not using any medication and gave informed consent to participate in the study.

Patients were randomly divided into two groups according to treatment. The patient in group A was treated with semi-conductive GaAlAs laser (BTL 2000 therapeutic laser - company Beautyline Technology Laser, Czech Republic) emitting radiation of $830 \mathrm{~nm}$, with maximal output of 100 $\mathrm{mW}$ and received $3 \times 36 \mathrm{~J}$ during one week postoperatively. The laser gives a spot size of approximately $0,5 \mathrm{~cm}^{2}$, the energy density per point was $12 \mathrm{~J}$, and power density $200 \mathrm{~mW} / \mathrm{cm}^{2}$. The lingual and buccal bony wall of extraction wound was irradiated intraorally and the area of the submandible node extraorally. Treatment intervals were 10 minutes after extraction, and 1 and 3 days after extraction. The patient in group B was treated with an inactive placebo probe in the same exposure schedule.

Table 1. List of patients participated in this study

\begin{tabular}{lll}
$\begin{array}{l}\text { Pacient } \\
\text { No }\end{array}$ & Laser & Reason for the exclusion from the study \\
\hline & & \\
1 & active & 3rd. day - Alvogyl, cold \\
2 & placebo & 3rd. day - Alvogyl \\
3 & active & Did not come for thermographic examination the $8^{\text {th }}$ day after surgery and did deliver questionnaire \\
4. & placebo & Dalacin C (antibiotic) \\
5 & active & Dalacin C (antibiotic), 3. den - alvogyl \\
6 & active & Plogenzym (enzymatic preparat), Dalacin C(antibiotic) \\
7 & placebo & ------------ \\
8 & active & --------
\end{tabular}

Patients were treated with antibiotic since the removing of the third molar was complicated. It means when the surgery took long time and the bone had to be drilled.

Operations were performed by the same surgeon. By using $2 \mathrm{ml}$ local anesthesia containing articain 4\% with adrenalin 1: 200000 (Supracain, Léčiva, Czech Republic), the flap retraction, osteotomy, tooth extraction, cavity treatment and suturing were carried out. Only one low third molar was removed at a time. The unoperated contralateral side served as a control.

Patients evaluated the level of postoperative pain and swelling on $100 \mathrm{~mm}$ Visual Analog Scale in mornings and evenings during one week after wisdom tooth extraction (Table 2). These $100 \mathrm{~mm}$ scales were described " 0 - no pain or no swelling" and "10 - the worst possible pain". The surgeon assessed post-surgery check - up examinations (Table 3) and another dentist carried out the laser therapy and thermographic examinations. Thermographic measurements of local inflammatory were performed by ThermaCAM ${ }^{\mathrm{TM}}$ SC 2000 before extraction, 30 mins after extraction and $1^{\text {st }}, 3^{\text {rd }}, 5^{\text {th }}, 8^{\text {th }}$ days after extraction always before laser therapy. 


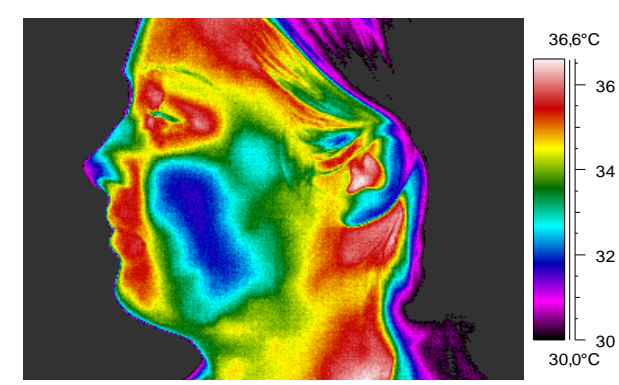

1a - before extraction

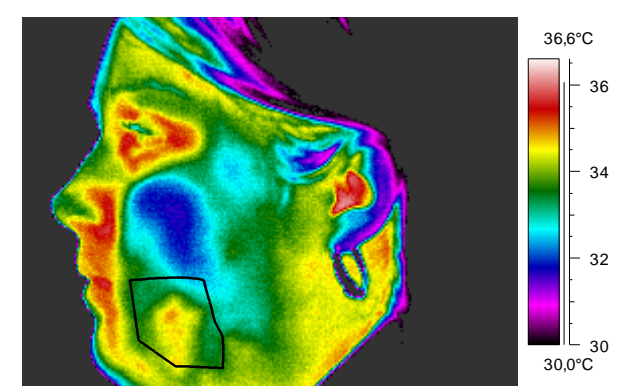

1c -3 rd. Day after extraction

Fig. 1. Thermogram of the patient treated by active laser
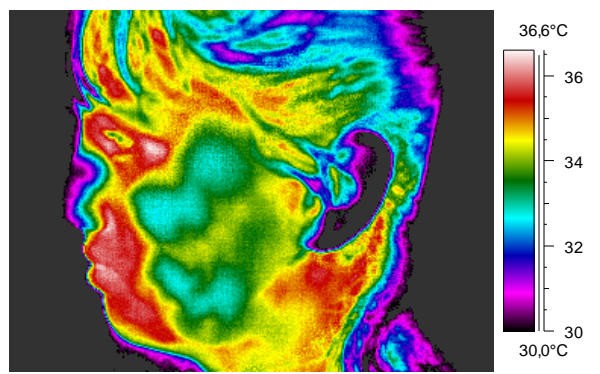

Fig. $2 \mathrm{a}$ - before extraction

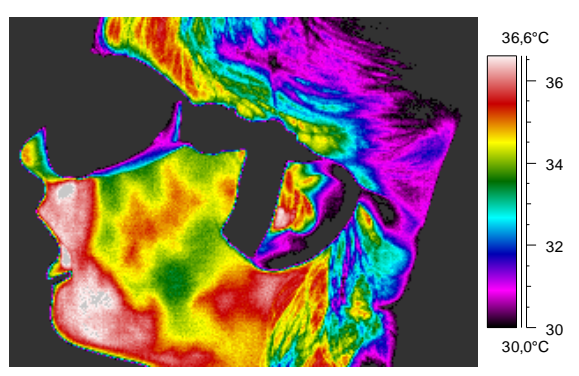

Fig. $2 c-3$ rd day after extraction

Fig. 2. Thermogram of the patient treated by placebo laser

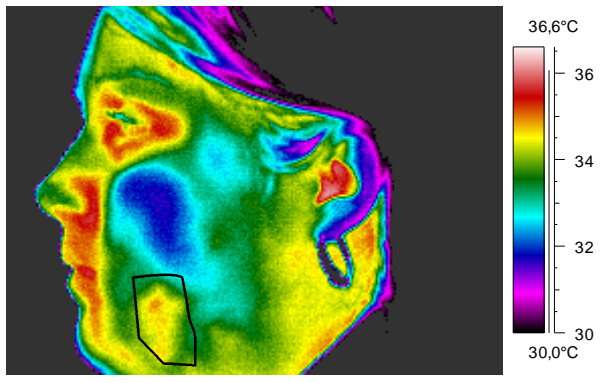

$1 b-1$ st. Day after extraction

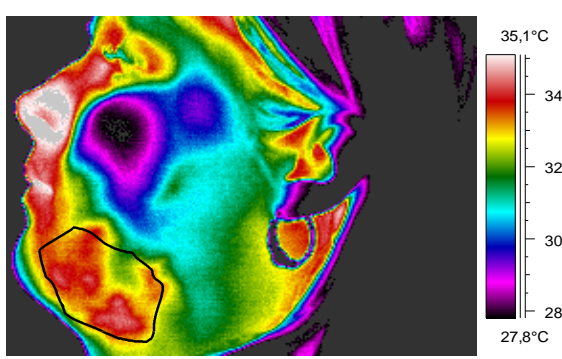

$1 \mathrm{~d}-8$ th day after extraction

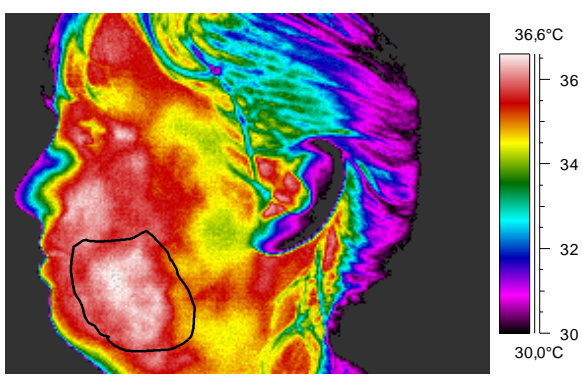

Fig. $2 b-1$ st day after extraction

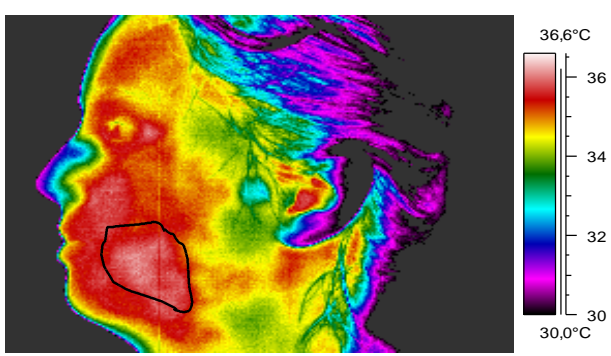

Fig. $2 d-8$ th day after extraction 


\section{RESULTS}

The thermographic picture of the face of patients before surgery is represented on figure $1 \mathrm{a}$ and $1 \mathrm{~b}$. The thermographic pictures of the face of the patient treated by active laser made the $1^{\text {st }}, 3^{\text {rd }}$ and $8^{\text {th }}$ day after extraction are represented on figure $1 b-d$. The thermographic pictures of the face of the patient treated by placebo laser made the $1^{\text {st }}, 3^{\text {rd }}$ and $8^{\text {th }}$ days after extraction are represented in figure $2 b$ d. The changes of the temperature of the face caused by surgical extraction in the patient treated by active laser and in the patient treated by placebo laser are demarked by a black line in the thermograms. The thermographic abnormalities caused by extraction remained longer in patient B who was treated by the placebo laser.

Table 2. Subjective assessment of average pain and swelling after extraction of impacted low third molars on $100 \mathrm{~mm}$ Visual Analog Scale.

\begin{tabular}{llllllll}
\hline A - active laser & $1^{\text {st }}$ day & $2^{\text {nd }}$ day & $3^{\text {rd }}$ day & $4^{\text {th }}$ day & $5^{\text {th }}$ day & $6^{\text {th }}$ day & $7^{\text {th }}$ day \\
\hline Pain & 26 & 27 & 25 & 22 & 3 & 7 & 6 \\
Swelling & 78 & 77 & 70 & 15 & 16 & 9 & 7 \\
Analgetic drugs & --- & --- & --- & --- & --- & -- & --- \\
B - placebo laser & 29 & 26 & 14 & --- & --- & --- & --- \\
Pain & 79 & 79 & 61 & --- & --- & -- & --- \\
Swelling & 3 & 2 & ---- & --- & -- & -- & -- \\
Analgstic drugs & & & & & & & \\
\hline
\end{tabular}

Table 3. Clinical assessment

\begin{tabular}{|c|c|c|c|c|}
\hline A - active laser & $1^{\text {st }}$ day & $3^{\text {rd }}$ day & $5^{\text {th }}$ day & $8^{\text {th }}$ day after surgery \\
\hline Mouth opening & 2 & 2 & 1 & 0 \\
\hline $\begin{array}{l}\text { Swelling } \\
\text { B - placebo laser }\end{array}$ & 2 & 2 & 1 & 1 \\
\hline Mouth opening & 0 & 0 & 0 & 0 \\
\hline Swelling & 2 & 1 & 1 & 0 \\
\hline
\end{tabular}

Mouth opening: 0- any limitation, 1- mild limitation, 2- severe limitation

Swelling: 0- none, 1- mild, 2- severe

\section{DISCUSSION}

The recovery of an extraction wound is always associated with an inflammatory reaction of the organism. The inflammatory reaction is characterized by a local increase in temperature, swelling, pain and impairment of function in the inflicted area. The most frequent criterion used for the assessment of the anti inflammatory treatment efficacy is a subjective evaluation of the level of pain by the patient.

The trickiness and inaccuracy of the monitoring of healing process based only on the patient's evaluation of the level of pain can be demonstrated by the results of this study. Patient B who reported less pain, took more analgesic drugs than patient $\mathrm{A}$ who reported more pain and took no drugs (Table 2). 
The infrared thermography is non-contact, nonionizing diagnostic method based on the exact recording of the temperature of the surface of the imaging area. Although the infrared thermography is not able to image anatomic changes, it is a sensitive diagnostic tool for the showing of vascular dysfunction (Special report: www.thermascan.com), impairment of sympathetic nervous system (Gratt et al. 1995, Shetty et al. 1994, McGimpsey et al. 1999) and sensitive innervation disorders (Uematsu S 1985, Bonezzi et al 1996, Santiago et al. 2000). The results of the studies (Biagioni et al. 1996, Ventä et al. 2001) imply that infrared thermography is able to precisely quantify clinical and subclinical inflammatory changes.

In our preliminary study the thermographic examination revealed the dissimilarities in the recovery of the extraction wound in patient $\mathrm{A}$ (treated by active laser) and patient7 B (treated by placebo laser). Temperature abnormalities caused by surgical extraction of the third molar were not present in patient $\mathrm{A}$ the 8th day after extraction. The thermographic picture of the face of the patient A was the same the 8th day after surgery as the thermographic picture made before extraction. However, the temperature abnormalities caused by surgical extraction of the third molar in patient B were still present on the thermographic picture the 8th day after extraction. Thermographic examination confirmed the biostimulating effect of the low power laser. In accordance with other our studies (Navrátil et al. 2000, Navrátil et al. 2003) the irradiaton of the low level laser accelerates the recovery of the extraction wound and reduces the time of treatment of the extraction wound in patient A.

The anti-inflammatory and biostimulating effects result from the activation of natural repairing processes occuring as a reaction of the organism to the inflammation in the course of the aimed laser application. The low power laser accelerates the reaction of the organism by activation of biochemical mediators and enzymes of the respiratory chain and by the accelerated rate of the metabolism in the irradiated tissue. The low power laser also supports the penetration of fibroblasts into the wound and activates the formation of collagen fibres (Navrátil et al 2000).

However, subjective assessment of the level of pain by the patients and clinical assessment of swelling and the jaw mobility did not correlate with the results of the thermographic measurements. Patient A reported a higher level of pain and swelling than patient B (Table 2). The reason for the pain and discomfort reported by patient A could be explained by hyperemia caused by use of the active laser (Navratil et al. 1996). According to this preliminary study we do not recommend the use of the low level laser for reduction of pain after dental surgery in the therapeutic schedule mentioned above.

We are aware of the shortcomings of this preliminary study resulted from the small study population. Further studies on a larger population are necessary to be able to statistically assess the relationship between applied energy density, changes of skin temperature in the region above extraction, patient's feelings and the progress of extraction wound healing.

\section{CONCLUSION}

Only two patients could be included for the assessment of effect of low power laser on wound healing. Therefore we can not make any valid conclusion from this preliminary study. However, it seems that infrared thermography promises to become a research tool for an objective assessment of anti-inflammatory treatment efficacy. According to thermographic examination and patients'questionnare the treatment with GaAlAs diode laser, $830 \mathrm{~nm}$ and total energy density for one treatment session $36 \mathrm{~J}$ accelerated extraction wound healing but did not reduce pain after dental surgery. Further studies on a larger population are necessary to obtain valid results and to be able to work out an optimal treatment plan minimalizing post-operative pain.

\section{ACKNOWLEDGMENT}

The authors acknowledge the help of the TMV-SS s.r.o Prague for lending the infrared camera and for technical advices.

This study has been carried out thanks to granted project GAUK No 1/ 2001 and the research project of the Ministry of education, youth and sports of the Czech Republic, No. FJ MSM 111100005.

Received $19^{\text {th }}$ March 2003.

Published online $12^{\text {th }}$ June 2003.

\section{REFERENCES}

Biagioni P.A., J.G. McGimpsey, P-J Lamey: Electronic infrared thermography as a dental research technique. Br. Dent. J. 180: 226-230, 1996. 
Bonezzi C, D. Miotti, Demartini, G.D. Volta: Thermography and chronic pain syndromes. Thermologie Österreich 6: 62-65, 1996.

Garcia G.A., F.S. Gude, J.R.Gandara, P.V.Gandara, M.M.Somoza: Pell-Gregory classification is unreliable as a predictor of difficulty in extracting impacted lower third molars. Br. J. Oral Maxillofac. Surg. 38: 585-587, 2000.

Gratt B. M., V. Shetty, M. Saiar, E. A. Sickles:Electronic thetmography for assessment of inferior alveolar nerve deficit. Oral. Surg. Oral Med. Oral Pathol. Oral Radiol. Endo. 80: 153-160, 1995.

Mc Gimpsey J.G., A.Vaidya, P.A.Biagiony, P-J. Lamey: Role of thermography in assesssment of infraorbital nerve injury after malar fractures. Br. J. Oral Maxillofac. Surg. 37: 581-584, 1999.

Santiago S, T. Ferrer, M. L. Espinosa: Neurophysiological studies of thin myelined (A delta) and unmyelited (C) fibers: application to peripheral neuropathies. Neurophysiol. Clin. 30: 27-42, 2000.

Shetty V., B.M.Gratt, V Flack: Thermographic assesment of reverzible inferior alveolar nerve deficit. J. Orofacial. Pain. 8: 375-383, 1994.

Simunovic Z. (ed): Lasers in medicine and dentistry. DTP studio Vitagrad, Rijeka, 2000.

Special report. Joint Council of State Neurosurgical societies of American Association of Neurological Surgeons and the Congress of
Neurological surgeons. Available at http://www.thermascan.com

Navrátil L, I. Dylevský: Mechanisms of biostimulating effects of therapeutics laser in vivo. Sborn. lék. 97: 521-527, 1996.

Navrátil L.(ed): Modern phototherapy and laser therapy (in Czech). MANUS, Praha, 2000.

Navrátil L, B. Navrátilová: Possibilities of the treatment of certain diseases in stomatology with the help of noninvasive laser therapy. Progress in Biomedical Optics and Imaging.37: 273-279, 2000.

Navrátil L, B.Navrátilova, J. Knížek, Z. Erösova, H. Fikáčkova, J. Kymplová: Possibilities of current use of non-invasive laser therapy and systemic enzymotherpy in stomatology. J. appl. Biomed. 1: 13-19, 2003.

Tunér J., L. Hode (ed): Low level laser therapy. Clinical practice and scientific backgraund. Prima Books, Sweden AB, 1999.

Uematsu S.: Thermographic imaging of cutaneus sensory segment in patients with periferal nerve injury: skin - temperature stability between sides of body. J. Neurosurg. 62: 716-720, 1985.

Ventä I., T. Hyrkäs, I. Paakkari, P. Ylipaavalniemi: Thermographic Imaging of postoperative inflammation modified by anti-inflammatory pretreatment. J. Oral Maxillofac. Surg. 59: 145-150, 2001.

\section{* Address:}

Hana Fikáčková, Institute of Biophysiscs and Informatics, $1^{\text {st }}$ Medical Faculty of Charles University, Salmovská 1 , 12000 Praha 2, Czech Republic; hfikackova@hotmail.com 